\title{
What counts in number books? A content-domain specific typology to evaluate children's books for mathematics
}

\author{
Julie Nurnberger-Haag ${ }^{\mathrm{a}}$, Anita N. Alexander ${ }^{\mathrm{a}^{*}}$, and Sarah R. Powell ${ }^{\mathrm{b}}$ \\ aSchool of Teaching, Learning \& Curriculum Studies, Kent State University, Kent, Ohio, USA; 'bepartment of Special \\ Education, The University of Texas at Austin, Austin, Texas, USA
}

\begin{abstract}
Although the complexity of children's number learning is recognized, trade books about number have been treated as a simple, undifferentiated set. This analysis of 186 children's books, however, categorized a distinct subset of books about number as counting books. These counting books were complex with regard to portrayal of counting sequences, explicitness of counting, and degree of rationality. The analysis yielded the multi-dimensional Counting Book Typology, which revealed nuanced ways counting books accurately portray numerical ideas as well as ways books could mislead young readers. The typology could aid researchers investigating how children learn with books to focus study design decisions on particular mathematics content features, which would clarify and strengthen resulting implications. Furthermore, this study revealed the need for more such conceptual tools to advance theorizing about learning math with children's books, which has been missing in research and practice.
\end{abstract}

\section{ARTICLE HISTORY}

Received 28 June 2017

Revised 26 May 2020

Accepted 30 May 2020

\section{KEYWORDS}

Counting; early childhood mathematics; literature; number; children's books; typology

The foundations of number children develop from ages 3 to 6 may be crucial to their mathematical performance as adolescents (Baroody et al., 2009; Claessens \& Engel, 2013; Watts et al., 2014). Perhaps more surprisingly, early numeracy has also predicted eighth-grade reading comprehension and science achievement (Claessens \& Engel, 2013). Long before formal school instruction, parents, other caregivers, and media begin exposing children to numbers through sources such as children's books. Increasingly, researchers have encouraged parents and teachers to read children's books about mathematics more often in both informal home and formal school settings (R. Hojnoski et al., 2016; R. L. Hojnoski et al., 2014). Yet, studies making these recommendations have selected books primarily on the criterion that the books included a mathematics topic without further analysis about how the books portrayed these topics.

A few content analyses have provided overviews of the characteristics of children's books about shape and number (Nurnberger-Haag, 2017; Powell \& Nurnberger-Haag, 2015; Ward et al., 2017). Such frequency-based characterizations of particular content topics were an important first exploration to understand potential sources of mathematics learning in this nascent area of research. The field, however, still lacks understanding about the quality and characteristics of the mathematical content in books and how these relate to learning outcomes when read with children (Flevares \& Schiff, 2014; Hachey, 2015). Thus, the purpose of this study was to better clarify the characteristics of these resources to provide a stronger foundation on which future research of learning outcomes can build.

CONTACT Julie Nurnberger-Haag jnurnber@kent.edu Graduate School of Education, Bilkent University, Ankara, Turkey *Current Affiliation: Graduate School of Education, Bilkent University, Ankara, Turkey (-) Supplemental data for this article can be accessed on the publisher's website. 
Trade book is a term librarians, publishers, and literacy-focused researchers use for books available to the public, rather than part of a textbook series. Given that educators overwhelmingly favor using children's trade books to supplement mathematics instruction, educators need "an instructional tool [to] be developed that will highlight for teachers the different ways in which they and others use children's literature to teach mathematics" (Cotti \& Schiro, 2004, p. 329). A methodological approach that would yield such a tool is to develop a typology (Delbridge \& Fiss, 2013; Smith, 2002). To provide this necessary tool, we analyzed trade books about number with the intent that researchers and teachers could use the tool to quickly categorize books according to mathematical features to identify potential problems and affordances for learning. This resulted in the Counting Book Typology.

\section{Rational and rote counting by ones}

We define number words as the oral and written words used to describe quantities in a person's language(s). By age two children commonly say and understand many spoken number words (Brooks et al., 2011). Rational counting is the process of meaningfully counting objects, fingers, sounds and so forth using all counting principles (Rea \& Reys, 1970; Reys et al., 2014; Saxe, 1977). The counting principles children implicitly use to accurately count objects are: stable order of oral number words, one-to-one correspondence between stating a number word and an object, order irrelevance (i.e., the objects in a set can be pointed to in any order), abstraction (quantity is an attribute), and cardinality (Gelman \& Gallistel, 1978; Gelman \& Meck, 1983). Knowing the concept of cardinality is greater than the procedural meaning originally defined by Gelman and Gallistel (1978). Being a cardinality-knower means having a conceptual understanding that a number can represent "how many." Individuals can also determine cardinality without counting. This is called subitizing, coined from the Latin term for "sudden" (Kaufman et al., 1949). If children have mastered stable order, but are still learning to meaningfully count objects, we can acknowledge this knowledge as rote counting (Reys et al., 2014; Saxe, 1977). By the end of kindergarten children in the U.S. are expected to rote count from one to 100 , count on from any number within that range, and rationally count up to 20 objects (National Governors Association Center for Best Practices \& Council of Chief State School Officers, 2010). Mapping written numerals to ideas of number is a critical skill; however, this is not considered part of the counting principles framework.

Children also need to learn that 0 (zero) is a valid number to describe the cardinality of a set without any objects (among other meanings) and that it precedes one. This developing understanding about the relative orders and magnitudes of cardinal numbers includes identifying and explaining whether a number is greater or less than another (Sarama \& Clements, 2009). Another learning goal is to understand each successive counting number is one more than the last. Although children will not use algebraic notation, we can model this meaning as $n+1$, where $n$ is a natural number (Le Corre \& Carey, 2008). Moreover, children must understand each successive natural number contains all prior and from this, develop the idea of composite units in which numbers can be thought of as units themselves (Kamii, 1986; Steffe, 1983). Ordinal words, such as first, second, and third that differ in English from one, two, three are also important numerical concepts for children to understand (Sarama \& Clements, 2009).

Kindergarten students should also solve addition and subtraction problems with the aid of physical objects using these numbers, while first-grade students should develop all of these numerical competencies within 100 (National Governors Association Center for Best Practices \& Council of Chief State School Officers, 2010).

\section{Skip counting: counting by a scalar other than one}

Composing and decomposing quantities with multiple iterations of same size groups helps children learn to skip count with meaning (i.e., counting by a scalar other than one to skip count rationally). To tell time on an analog clock, children need to count by fives; to count money children need to count by 
5 and other scalars such as 10 or 25 (Frank, 1989). Moreover, counting money requires switching between scalars when the scenario warrants it. It is through thinking about the individual objects within skip-counted groups or grouping and regrouping that children develop ideas consistent with place value to think of a group of ten objects as a higher-order unit or composite unit, called a "ten" (Fuson \& Secada, 1986; Kamii, 1986; Steffe et al., 1988).

\section{Using trade books to teach mathematics}

Books are one resource parents and other adults use to teach children early numeracy (Gaylord et al., 2020). Although such books are just one environmental exposure to such concepts, the quality of such books warrants investigation for what children would have the opportunity to learn from them, yet this has received little attention in mathematics education research (Hachey, 2015; Nurnberger-Haag, 2017). Science education is more advanced in this regard, because researchers have critiqued the science content in trade books and documented that children learned this content regardless of whether it was accurate (Mayer, 1995; Rice, 2002). Thus, disciplinary content of books matters for learning. Despite a lack of analyses of mathematics content, standards as well as claims in study implications have recommended that parents and teachers use books to help children learn mathematics (Anderson et al., 2004; R. Hojnoski et al., 2016; R. L. Hojnoski et al., 2014; National Governors Association Center for Best Practices \& Council of Chief State School Officers, 2010; Van de Walle et al., 2012). Future research on learning with books would be strengthened by first better understanding and reporting how the particular books used portray mathematical ideas.

\section{Existing rubrics to evaluate books for mathematics learning focus little on math}

Existing rubrics to evaluate children's books for mathematics instruction include a statement encouraging accuracy of mathematics content. These rubrics use Likert scales to analyze the criteria of overall mathematical accuracy and then average this rating with four to five other category scores (e.g., Hellwig et al., 2000; Hunsader, 2004; Marston et al., 2013; van den Heuvel-Panhuizen \& Elia, 2012). Thus, accuracy has been only one of many criteria, which makes the mathematics subservient to other characteristics such as "wow" factor (Hellwig et al., 2000, p. 139; Hunsader, 2004; Marston et al., 2013; van Den Heuvel-panhuizen \& Elia, 2012). In other words, in spite of the book being used to teach mathematics, these rubrics have marginalized the importance of mathematics as a criterion.

\section{Mathematical quality criteria unclear in existing rubrics}

Even those rubrics that include mathematical quality have unclear criteria, because these rubrics use Likert scales. What does it mean to have an average or even above average rating of mathematical quality? Without a theoretical frame or specific criteria for what counts as mathematically accurate or productive, how adults rate and select such books for children varies based on these adults' mathematical knowledge (Nesmith \& Cooper, 2010). Given issues with the mathematical knowledge of elementary teachers and adults in general (Campbell et al., 2014), the field needs more specific criteria to analyze the mathematics in children's books. At a minimum, research should delineate separate criteria for each domain of mathematics portrayed in children's books (Nurnberger-Haag, 2017).

\section{Definitions of number books}

Although terms were not usually operationalized in prior studies, based on children's books selected in each study, we infer that researchers seem to agree that number books require at least several occurrences of number, if not number as the primary objective of the book. Powell and NurnbergerHaag (2015), who operationalized the terms, defined number books as books that either were entirely focused on number or included pages about numbers. In contrast, others have labeled books with these same characteristics counting books (Hellwig et al., 2000; Ward et al., 2017). The juvenile nonfiction concepts category that libraries and publishers use to refer to such books is Numbers and Counting (Book Industry Study Group, 2016), also without definition or distinction. Recent research 
in the field of child development has also treated the definition of counting books as self-evident for a researcher audience as well as in parental surveys with questions such as: "How often do either you or your partner read counting books to your child?" (Gaylord et al., 2020, p. 4). Although from the list of books, these researchers seemed to use an implicit operating definition that numbers presented in sequence were counting books, it is unknown whether parents think of the term counting books the same way.

\section{Characteristics of number books}

The field knows little about the mathematical qualities of children's books (Hachey, 2015), but two studies began to describe these characteristics for books about number. First, Powell and NurnbergerHaag (2015) analyzed 160 children's trade books found in elementary school libraries, through an Amazon search, and within a literacy colleague's personal collection that addressed "number" or "counting." Second, Ward et al. (2017) selected 120 trade books intended for children from birth to 5 -years-old that contained the numbers 1,2 or 3. Both of these studies reported descriptive statistics.

Which numbers are in children's books. Children have limited exposure in their environment to numbers greater than 10 as well as little exposure to the number 0 (McDonald, 2007; Powell \& Nurnberger-Haag, 2015; Ward et al., 2017). In the preschool book study, for example, $79 \%$ of books included numbers only less than or equal to 10 (Ward et al., 2017). Even in a sample that included books for older children, 68\% stayed within 10 (Powell \& Nurnberger-Haag, 2015). Both of these prior studies found less than $10 \%$ of books presented zero as a number by using a numeral " 0 " or word "zero" (Powell \& Nurnberger-Haag, 2015; Ward et al., 2017, p. 54). This leaves little opportunity for children to develop concepts of numbers or the patterns in the number system from these books.

How images related to written symbols. Whether books related counts to images of objects have also been documented (Powell \& Nurnberger-Haag, 2015; Ward et al., 2017). For instance, Powell and Nurnberger-Haag (2015) determined 79\% (126) of 160 books displayed the numeral or number word of the cardinality shown (e.g., 4 or "four") without counting each object for the reader (e.g." "1, 2, 3, 4"; Powell \& Nurnberger-Haag, 2015). Only 14\% of the pictures in the 120 preschool books showed the total objects grouped in two or more sets, which could support developing number sense and foundations of addition and subtraction (Ward et al., 2017).

Number sequences. In terms of number sequences, prior studies focused on whether numbers were sequential in the text, whether skip counting occurred, and by which scalars the book skip counted. The study of books for ages birth through early elementary school coded numbers as whether these were "presented in a sequence" (Powell \& Nurnberger-Haag, 2015, p. 387), whereas the preschool study coded whether numbers were "out of sequence" (Ward et al., 2017, p. 54). Both of these ways warrant unpacking. The purpose of Powell and Nurnberger-Haag's (2015a) approach was to distinguish between books in which a child could rote count to predict the next number in the sequence without attending to cardinality (88.8\% of 160 books; Powell \& Nurnberger-Haag, 2015) separately from books that labeled a cardinal set with a numeral in an unpredictable sequence. Such books described as presented in a sequence in Powell and Nurnberger-Haag (2015) referred to any books that provided a sequence, regardless of whether that sequence was a mathematically consistent sequence. In contrast, Ward and colleagues' finding that $41 \%$ of 120 books were presented "out of sequence" included books that labeled a cardinal set in an unpredictable sequence as well as books that presented sequences in which at least one number was not the next number in the established sequence (Ward et al., 2017). Yet, each of these characteristics may have different learning affordances that warrant more careful investigation about ways number sequences are shown to children.

Recall the selection criteria in Ward et al. (2017) sample required that the book include the number 1,2 , or 3 . Mathematically then it is unsurprising that just $6 \%$ of books included skip counting, because the only valid scalars would be two or three. Whereas, in a sample that included books appropriate for 
elementary school children, $12.5 \%$ of 160 books skip counted by two, four, five, and/or ten (Powell \& Nurnberger-Haag, 2015). Thus prior research documented what sequences were shown, yet left open questions about how books portray such numerical sequences.

\section{Methodological gaps}

The methodological approach used in prior analyses of children's books was first to define expected characteristics, code for these, and report descriptive statistics of how frequently these characteristics appeared in the sample of books. This method provided some indication of what is available for purchase and in libraries; however, it obfuscates potential learning affordances and issues in many ways. For example, each of these studies reported the percent of books that skip counted, percent that showed numbers "out of sequence," and the percent of books that showed a picture for the meaning of a written numeral or number word. These statistics reflect the likelihood that when choosing a book it would have each of these single characteristics. Although this was an important first step when no research existed, such research fails to consider which characteristics co-occur in these books. More importantly a more nuanced understanding of how these books portray numbers is needed before conducting studies about what, how, and why children might learn particular ideas with such books and adults who read with them. For example, how do these trade books portray sequences of number? Do the words in these books tell the reader they are skip counting or counting in a new way or are readers left to infer these ideas? Are skip counting sequences simply sequences of numerals or number words without supporting images (rote counting), or if images are shown (rational counting), how do the images portray the skip counting sequence(s)?

Daycares, preschools, homes, and early elementary classrooms typically have some books about numbers. For illustration's sake, let's say six. The quality or opportunity to learn with those six books, which the child is likely to repeatedly reread, is what matters, not how likely it was that the six books in the children's home or classroom have each characteristic. Thus, how multiple features of a particular book or books work together to create varied learning opportunities should be better understood. This requires more focused analysis of the books themselves before considering how children use these complex resources.

\section{Theoretical and methodological perspectives}

Claims are commonly made that teaching math with children's books is so important that it should be more prevalent; however, this is a broad generalization that should be recognized as history repeating itself. The same generalized claims were made about benefits of manipulatives, which the field later corrected (Ball, 1992; Friedman, 1978). Although more research on characteristics of manipulatives to understand potential learning affordances and issues is needed (Nurnberger-Haag, 2018a), our field now recognizes it is inappropriate to claim manipulatives are universally beneficial or problematic. Most prior research on learning mathematics with children's books, however, has repeated the historical mistake and jumped to the implementation level without attending to the characteristics of specific books used. This prevents clarity about what, why, and how students learn with these books. Before researching how children (often along with adults) use books to learn mathematics, a first step should be to identify features and articulate potential learning affordances of selected books. The current study provides insight about the nuances of children's counting books.

Theories of learning such as constructivism or situated cognition can be used in research on children's use of books for mathematics. These broad theoretical stances, however, are insufficient to understand how and why students might learn with books. More specific theorizing and theoretical tools are needed. Just as our field has developed tools such as van Hiele levels (van Hiele, 1986) for geometry, the Cognitive Demand Framework (Stein \& Smith, 1998) for mathematical tasks, and the taxonomy for students' generalizing actions (Ellis, 2007), our field needs conceptual research tools such as frameworks, taxonomies, and typologies specifically about learning mathematics with children's books. 
Typologies are a rigorous form of classification, whereas "lack of proper classification" impedes a field from developing coherent theories (Collier et al., 2012; Niknazar \& Bourgault, 2017, p. 196). Thus, a lack of classification of children's books used for mathematics has inhibited our field from understanding the impact these books could have on learning. The classification available thus far has been at a broad level focused on the purpose of the book in terms of perceived genre. This perception, however, varies by discipline. The way mathematics education researchers have framed this purpose is different than the way literacy educators or psychologists categorize these types when conducting research. The mathematics education classification for using books to teach math, although not identified as such, is essentially a unidimensional typology consisting of three types: literature stories that could be mathematized, stories created to show math, or math (Marston et al., 2013; Shih \& Giorgis, 2004).

Although such broad categories of children's books may be easy to use, small differences can matter (Petersen et al., 2014). No typologies have classified books based on features of the mathematical ideas. Typologies provide "a set of related but distinct categories within a phenomenon that discriminate across the phenomenon" (Ayres \& Knafl, 2008, p. 901). Typologies can be multidimensional to cross tabulate two or more categorical or ordinal variables, such that the specific cells characterize the phenomena into mutually exclusive types (Ayres \& Knafl, 2008; Collier et al., 2012).

Developing a typology is theorizing (Delbridge \& Fiss, 2013). This theorizing could yield either an explanatory typology or a conceptual typology (Collier et al., 2012). If this theorizing develops an explanatory typology, the product is a tool that clarifies a theory or creates a new theory. A conceptual typology is a research tool that a) supports subsequent empirical testing of the implications of each type and b) provides a tool upon which diverse theories can draw or a foundation from which new theories develop (Collier et al., 2012; Swedberg, 2012). Conceptual typologies (also known as Descriptive typologies) are particularly important when an area of research is just emerging (Collier et al., 2012), which is the status of research on the mathematics of children's books. Research conducted without such conceptual foundations can lead to studies with competing findings (Vasquez, 1993, as cited in Collier et al., 2012).

\section{Focus of present study}

Nurnberger-Haag (2017) identified inaccuracies as the primary issue with books about shapes, so it is important to uncover in what, if any, ways books imply or explicitly show inaccuracies about number. Moreover, accuracy (e.g., Hellwig et al., 2000; Hunsader, 2004) is a necessary but insufficient criterion to understand potential learning affordances of children's books for mathematics. Just as careful attention has been given to resources for learning such as mathematical tasks (e.g., Stein \& Smith, 1998), similar attention must be paid to the learning opportunities provided in children's books. Rather than what adults and children do with number-related books in formal and informal learning contexts, this study describes characteristics of books as opportunities for learning. Toward this end, qualitative analyses of books about number yielded findings that were broader, deeper, and more multifaceted than anticipated, which warranted an entire article on sequences of numbers (a separate article is needed to fully address number representations). Consequently, this article reports the development of the Counting Book Typology as a conceptual lens through which to view children's books with arithmetic sequences for their learning affordances.

\section{Method}

Rather than to tell researchers or teachers how often a particular type occurred in a sample, our purpose was to help these professionals view any given book through conceptual lenses that could inform their selection and use of specific books with children. Consistent with this purpose, the categories of the typology are the findings of this study. Thus, this section broadly describes the development process, and reports the validation process. 


\section{Development of counting book typology}

The typology developed from a qualitative analysis of a subset of books selected from a quantitative study (Powell \& Nurnberger-Haag, 2015). The books analyzed were those that included skip counting, superordinate and subordinate units (i.e., two distinct types of items represented a whole set [e.g., a set of oranges and a set of apples represented a total set of fruit]), and visual grouping (i.e., items in a pictorial representation were grouped together on a page to constitute a set). Other books that included the numbers 0 or 100 were included in the analysis because these were the least and greatest numbers that occurred at least twice in the 160-book sample in Powell and Nurnberger-Haag (2015). Due to the dominance of books that included the number 10 (Powell \& Nurnberger-Haag, 2015), 10\% of books with the number 10 were randomly selected for more qualitative analysis. This resulted in the 65-book sample (see Table S1 in the online supplementary materials).

Each book was the unit of analysis to determine how books treated numbers in terms of the types of sequences, explicitness of counting, and whether counting was portrayed as rote or rational. Using qualitative tools described in Saldaña (2013), Phase I consisted of writing analytic memos, Phase II consisted of open coding of skip counting sequences, and Phase III used axial coding to refine categories and definitions, which resulted in a multidimensional conceptual typology of counting books. Appendix A in the online supplementary materials documents the development process in depth, which readers would find most helpful after reading the Findings.

\section{Validation of typology}

To locate books to which parents and teachers from varied socioeconomic communities would have access, we collected all number-related books available on the date of collection at three public libraries from an upper-income suburban town, middle-income town, and the main branch of an urban library. This resulted in a validation sample size of 126 books (see Table S2 in the online supplementary materials). Thus, the typology was validated with a sample that was almost twice as large as the sample from which the typology was empirically derived $(n=65)$.

Two coders who were not part of the development of the typology were trained. One coder was a former elementary teacher and doctoral candidate. The second coder was an undergraduate prospective elementary teacher. The validation coding confirmed number-related books were identifiable and that counting books was a subcategory with $100 \%$ inter-rater agreement. Each subcategory of counting books exceeded or neared the threshold of $90 \%$ inter-rater agreement: Sequence Type (90.5\%), Explicitness (89.7\%) and Rationality (96.8\%).

\section{Findings}

This analysis led us to define number-related books to reflect the broadest category with at least two instances of number appearing in the book. Whether the authors intended to teach readers about number is irrelevant to these definitions. More importantly, we specified counting books as a welldefined subcategory of number-related books that count for readers by presenting numbers in a sequence in at least one of two ways. Either the entire book consists of an arithmetic sequence of at least three numbers (numerals, number words, or visual representations), or alternatively, a counting book is defined as a number-related book with at least two such arithmetic sequences of three numbers. These sequences may be increasing or decreasing. Note that repetitions of numbers do not satisfy an arithmetic sequence even if these are generally in increasing or decreasing order (e.g., 5, $5,5,10,10,15)$.

A book that uses the word "count" will likely be a number-related book; however, it may not be a counting book. Counting at the Zoo (Rauen, 2008) was a number-related book, because in at least two instances it displayed a written numeral to draw attention to the quantity or how many objects or animals were on each page. Despite the use of the word "counting" in the title, however, Counting at 
the Zoo (Rauen, 2008) did not constitute a counting book because the author presented numerals in an unsystematic order (i.e., not presented in an arithmetic sequence of at least three numbers; except in one instance of "1, 2, 3, wolves"). Children could count the animals in Counting at the Zoo and the book stated the cardinality on each page, but the book itself did not perform counting actions for children.

The broadest level categorizations of a typology can be multidimensional (Smith, 2002). We found that each book could be viewed using the three dimensions: (a) Counting Sequences, (b) Explicitness of Counting, and (c) Rationality. The Counting Sequences dimension is the core dimension to use to identify the particular sequences portrayed with numerals and/or number words. The other two dimensions articulate to what degree the text (explicitness of counting) and pictures (rationality) specify any changes or patterns of numbers in the identified sequence.

\section{Counting sequences}

We determined whether a book displayed more than one arithmetic sequence, whether it used scalars of 1 or other scalars, and how the book changed scalars (i.e., started a new sequence or counted on with the new scalar). Figure 1 illustrates these aspects as hierarchical levels, whereas Table 1 defines each of the most specific subcategories. The second column of Table 1 identifies the code used to abbreviate each category name followed by the definition and at least one example from the data. These categories are described in subsequent sections.

\section{Single Sequence}

The Single Sequence category means the book showed exactly one sequence. Single Sequence consisted of three subcategories: Whole Number Counting (WC), Skip Counts (SC), and Ordinal Sequence (OS). Examples and definitions are provided in Table 1. The Whole Number Counting (WC) subcategory refers to a stable-order-counting sequence children first learn as toddlers and continue to learn throughout early childhood. Zero is not an element of the set of natural numbers (i.e., the counting numbers, $1,2,3, \ldots$ ) and, therefore, children begin counting with 1 rather than 0. Nevertheless, because zero is a whole number that, among other meanings, can be used to represent the absence of a count, it is an important numerical concept. Thus, we labeled this subcategory using the set of whole numbers $(0,1,2,3 \ldots)$. The Skip Counts (SC) subcategory refers to a single sequence of counting in a stable order by some scalar other than one, such as counting ones units in sets of twos, fives, tens, or so forth. The Ordinal Sequence (OS) subcategory refers to ordinal numerals or number words presented in a sequence of at least three increasing or decreasing ordinal numbers as shown in Table 1.
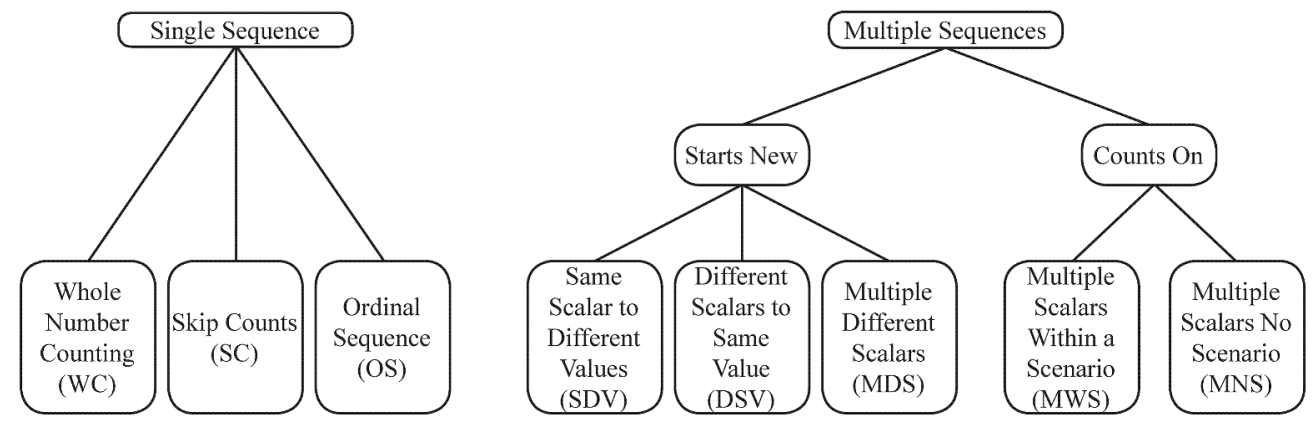

Figure 1. Counting sequence types. 
Table 1. Definitions and examples of counting sequence types.

\begin{tabular}{|c|c|c|c|c|}
\hline Category Terms & Code & Definition & Data Examples & Citation \\
\hline \multicolumn{5}{|l|}{ Single Sequence } \\
\hline $\begin{array}{l}\text { Whole } \\
\text { Number } \\
\text { Counting }\end{array}$ & WC & $\begin{array}{l}\text { An arithmetic sequence that increases or } \\
\text { decreases by one (the term whole numbers is } \\
\text { used rather than natural or counting numbers } \\
\text { to include 0) }\end{array}$ & $0,1,2,3, \ldots, 24,25,26$ & $\begin{array}{l}\text { Pallotta } \\
\quad(1991)\end{array}$ \\
\hline Skip Counts & SC & $\begin{array}{l}\text { A single counting sequence by a scalar other } \\
\text { than one }\end{array}$ & $\begin{array}{l}\text { FIVE, TEN, FIFTEEN, } \ldots, \text { FOURTY, } \\
\text { FOURTY-FIVE, FIFTY }\end{array}$ & Dahl (2005) \\
\hline $\begin{array}{l}\text { Ordinal } \\
\text { Sequence }\end{array}$ & OS & $\begin{array}{l}\text { Ordinal numerals or number words listed in } \\
\text { a sequence }\end{array}$ & First, Second, Third and Fourth & $\begin{array}{l}\text { Murphy } \\
\text { (1999) }\end{array}$ \\
\hline \multicolumn{5}{|l|}{ Multiple } \\
\hline \multicolumn{5}{|l|}{ Starts New } \\
\hline $\begin{array}{l}\text { Same Scalar } \\
\text { to Different } \\
\text { Values }\end{array}$ & SDV & $\begin{array}{l}\text { The book starts a new sequence to use the same } \\
\text { scalar. More than one sequence shown using } \\
\text { the same scalar, such as } 2 \text {. }\end{array}$ & $\begin{array}{l}0,2,4,6, \ldots 20,22,24 \\
\text { Then starts a new sequence with the } \\
\text { same scalar } \\
1,3,5, \ldots 19,21,23\end{array}$ & $\begin{array}{l}\text { Ryan \& } \\
\text { Pallotta } \\
(1996)\end{array}$ \\
\hline $\begin{array}{l}\text { Different } \\
\text { Scalars to } \\
\text { Same Value }\end{array}$ & DSV & $\begin{array}{l}\text { The book starts a new sequence to use } \\
\text { a different scalar. More than one sequence } \\
\text { shown using different scalars but the same } \\
\text { ending number. }\end{array}$ & $\begin{array}{l}4,8,12,16, \ldots 96,100 \\
\text { Then starts a new sequence with } \\
\text { different scalar } \\
5,10,15,20, \ldots 95,100\end{array}$ & $\begin{array}{l}\text { Franco } \\
\quad(2002)\end{array}$ \\
\hline $\begin{array}{l}\text { Multiple } \\
\text { Different } \\
\text { Scalars }\end{array}$ & MDS & $\begin{array}{l}\text { The book starts a new sequence to use } \\
\text { a different scalar. At least two physically } \\
\text { separated sequences with different scalars } \\
\text { also end at different values. }\end{array}$ & $\begin{array}{l}\text { On p. } 5-6: 2,4,6,8,10,12 \\
\text { On p. } 7-8: 5,10,15,20 \\
\text { On p. } 23-24: 1,2,3, \ldots 18,19,20\end{array}$ & $\begin{array}{l}\text { Markel } \\
\quad(2009)\end{array}$ \\
\hline \multicolumn{5}{|l|}{ Counts On } \\
\hline $\begin{array}{l}\text { Multiple } \\
\text { Scalars Within } \\
\text { a Scenario }\end{array}$ & MWS & $\begin{array}{l}\text { Multiple sequences are used, but rather than } \\
\text { starting over, the text counts on using } \\
\text { a different scalar within a real-life scenario or } \\
\text { context where it makes sense or is applicable } \\
\text { to use multiple scalars such as counting } \\
\text { money. }\end{array}$ & $\begin{array}{l}\mathbf{2 5}, \mathbf{3 0}, 40, \mathbf{5 0}, \mathbf{5 1}, 52,53 \\
\text { [Scenario consisted of counting the } \\
\text { value of a quarter, then a nickel, then } \\
\text { two dimes, then } 3 \text { pennies] }\end{array}$ & $\begin{array}{l}\text { Murphy } \\
\text { (1998b, } \\
\text { p. 11) }\end{array}$ \\
\hline \multirow{7}{*}{$\begin{array}{l}\text { Multiple } \\
\text { Scalars No } \\
\text { Scenario }\end{array}$} & MNS & $\begin{array}{l}\text { Multiple sequences are used, but rather than } \\
\text { starting over, the text counts on using }\end{array}$ & $\begin{array}{l}1,2,3, \ldots, 8,9,10,20,30, \ldots, 80,90 \\
100\end{array}$ & Sloat (1991) \\
\hline & & $\begin{array}{l}\text { a different scalar; however, no scenario or } \\
\text { context is used to make the change of scalar }\end{array}$ & $\begin{array}{l}1,2,3, \ldots, 8,9,10,10,20,30, \ldots, 80 \\
90,100^{\text {a }}\end{array}$ & $\begin{array}{l}\text { Lottridge } \\
\text { (1997) }\end{array}$ \\
\hline & & $\begin{array}{l}\text { sensible or uses a context that fails to make } \\
\text { the change of sequence sensible. }\end{array}$ & $\begin{array}{l}1,2,3, \ldots, 18,19,20,30,40, \ldots, 80 \\
90,100\end{array}$ & $\begin{array}{l}\text { Scarry } \\
(1975)\end{array}$ \\
\hline & & & $\begin{array}{l}1,2,3, \ldots, 18, \mathbf{1 9}, \mathbf{2 0}, \mathbf{3 0}, 40, \ldots, 80 \\
\mathbf{9 0}, \mathbf{9 9}, \mathbf{1 0 0} \\
1,2,3, \ldots, 13,14, \mathbf{1 5}, \mathbf{2 0}, \mathbf{2 5}, 30, \mathbf{4 0} \\
\mathbf{5 0}, \mathbf{1 0 0}\end{array}$ & $\begin{array}{l}\text { Martin } \\
\text { et al. } \\
\text { (2004) } \\
\text { Shepherd } \\
\text { (2007) }\end{array}$ \\
\hline & & & $\begin{array}{l}1,2,3, \ldots, 18,19, \mathbf{2 0}, \mathbf{1 0}, \mathbf{2 0}, 30, \ldots \\
80, \mathbf{9 0}, \mathbf{1 0 0}, \mathbf{0} \\
2,4,6, \ldots, 16, \mathbf{1 8}, \mathbf{2 0}, \mathbf{1 0 0 ^ { b }}\end{array}$ & $\begin{array}{l}\text { McGrath } \\
\text { (1998) } \\
\text { Schuette } \\
\text { (2003) }\end{array}$ \\
\hline & & & $1,3,5, \ldots, 45,47, \mathbf{4 9}, \mathbf{5 0}, 0$ & $\begin{array}{l}\text { Pallotta } \\
(2005)\end{array}$ \\
\hline & & & $\begin{array}{l}1,2,3, \ldots, 13,14,15,20,30,40, \ldots \\
80,90,100\end{array}$ & $\begin{array}{l}\text { Hoban } \\
(1972)\end{array}$ \\
\hline
\end{tabular}

Note. For each sequence type, the numerals or number words can be in an increasing or decreasing sequence as long as a pattern of three numerals or number words establishes a sequence.

ancluded extra page and repeated number

${ }^{\mathrm{b}}$ The entire sequence is also printed on every page

\section{Multiple Sequences}

Some books communicated to readers that counting can be done in various ways with different scalars, which we named Multiple Sequences. Some of these multiple sequences books portrayed a sequence and then started over to represent a new sequence: Starts New subcategory. A second 
subtype of multiple sequences continued counting on using a different scalar, which we labeled Counts On. Next we describe in detail the subtypes we found within Starts New and Counts On.

\section{Starts New}

Of those books that started sequences over (Starts New) we identified three ways that books did so: Same Scalar to Different Values (SDV), Different Scalars to the Same Value (DSV), and Multiple Different Scalars (MDS). Table 1 details the definitions and provides examples to differentiate these sequence types, which we next describe in more detail.

Same Scalar to Different Values. Mathematically, we would define a sequence with the initial value plus some scalar (e.g., $\mathrm{X}_{0}+\mathrm{nX}$ ) because the intent is that the sequence is infinite. In children's books, however, sequences are presented as though finite, so in the typology we named these based on the scalar and ending value. This SDV subtype shows skip counting by the same scalar by beginning and, thus, also ending at different values.

Different Scalars to the Same Value. The second subtype, DSV, displays multiple sequences to show readers that different ways of counting can include the same numbers. For example, each page of Many Ways to One Hundred (Franco, 2002) presented a different accurate counting sequence that can stop at 100. These were written in a list of numerals separated by commas. In addition to counting "by $1 \mathrm{~s}$," " $2 \mathrm{~s}$ ", "4 s", " $5 \mathrm{~s}$ ", and " $10 \mathrm{~s}$ ", this book also explained a non-example: counting by eight cannot yield the number 100 (i.e., $8,16,24 \ldots 88,96,104$ ).

Multiple Different scalars. The SDV and DSV codes just described were quite specific in that either the scalars (SDV) or the ending values (DSV) were the same. In contrast, a counting book that provided at least two separate and valid sequences using different scalars as well as different ending values yielded: Multiple Different Scalars (MDS) as shown in Table 1.

\section{Counts On}

Informed by children's counting strategies (Sarama \& Clements, 2009), we used "counts on" to recognize when counting books represented a skip counting arithmetic sequence with this counting strategy. Books in this sample that counted on from one number to the next using more than one scalar within a stated sequence did so in two ways, which we classified as subtypes of Counts On: Multiple Scalars Within a Scenario (MWS) or Multiple Scalars No Scenario (MNS). Bold font in Table 1 accentuates where changes of scalar occurred.

Multiple Scalars Within a Scenario. A book about counting money led us to identify the Multiple Scalars Within a Scenario (MWS) category. For example, The Penny Pot (Murphy, 1998) exemplified a context in which it was necessary and useful to change scalars while counting. The characters count their U.S. coins to see if they have 50 cents to have their faces painted at the fair. One character had a quarter, a nickel, two dimes, and three pennies, so the book showed pictures of the coins over each numeral to count (see sequence in Table 1). Hence, we named the category to reflect the idea of counting by different scalars, which is important for telling time as well as other real-life scenarios.

Multiple Scalars No Scenario. In contrast to MWS, we also found books that failed to provide a realistic scenario to justify changing scalars in the midst of counting. In other words, the Multiple Scalars No Scenario (MNS) type are books that change scalars while counting on in ways that omit contexts or scenarios that could have made a change sensible. Relationships with MNS and explicitness within the typology will be elaborated in the Discussion section.

Table 1 displays each MNS sequence found in the sample. Presented first are those MNS sequences that established a pattern (i.e., of at least three numbers) and then count on with a different scalar to 
establish another pattern. These are followed by the sequences that changed scalar but failed to establish a new pattern. When establishing the typology we defined these as Portrayed as Single Sequence (PSS) and Violates Established Sequence (VES), respectively. During the review process we simplified the typology by collapsing these categories into MNS. Notice that every MNS sequence type book ended with 0 or 100 .

Due to the popularity of the alphabet book Chicka Chicka Boom Boom (Martin et al., 1989), people are likely to buy the counting book Chicka Chicka 123 (Martin et al., 2004). Note in Table 1 that Chicka Chicka 123 (Martin et al., 2004) established patterns then violated its own established sequences three times. The text counted by ones to 20, but then counted on from 20 by tens which established another sequence of three numbers. Then the book violated this sequence by showing the numeral 99 without establishing a new pattern and then showed the numeral 100.

Notice in Table 1 that Eating Pairs (Schuette, 2003) established a sequence of skip counting by two from two to 20 with each turn of the page. It violated this pattern once by ending with the numeral 100 immediately after 20 . Unfortunately, the book repeatedly displayed this problematic sequence vertically on the far-right edge of every page in the book, so a young reader could see the numeral 100 portrayed as the next number after 20 a total of 11 times.

Husker Numbers is a "Nebraska Number Book" (Shepherd, 2007). The publisher created a book with the same set of sequences for every state in the U.S., making this a potentially appealing book for teachers seeking to integrate local social studies goals with mathematics. Consider in Table 1, however, how this MNS book portrayed numerical sequences. This book first counted by ones to 15, then appeared to count by fives without establishing a pattern of three instances, then counted on to establish a pattern of counting by decade numbers, but just to 50, then ended the sequence with 100 without naming any multiples of ten between 50 and 100 .

The author of the book Ocean Counting: Odd Numbers (Pallotta, 2005) inaccurately implied that 0 and 50 are odd numbers because most of the book, including the title, proclaimed the book was about odd numbers. Nevertheless, after skip counting odd numbers from 1 to 49 by twos, the authors decided to violate this pattern to present 50 sea animals, then included the number 0 by having all the animals swim away. Similarly, The Cheerios Counting Book skip counted by 10 resulting in 100 Cheerios on the second to the last page then abruptly on the next page ended the sequence with zero to imply they had all been eaten (McGrath, 1998, pp. 28-29).

\section{Explicitness}

The explicitness dimension documents how explicitly words informed the reader about counting. Table 2 provides definitions and data examples of explicitness types in order of decreasing explicitness: Explicit Scalar (ES), Explicit Counting (EC), and Implicit Counting (IC). Explicit Scalar categorized those books that told children they were "counting" as well as by what scalar. Explicit Counting meant the book told children they were "counting" in the title or in the text, but did not tell children by what value they were counting (i.e., scalar was implicit). Implicit Counting identified a book that presented numbers in one or more sequences (irrespective of whether these patterns were mathematically consistent), but never used the word "count." To clarify implicit counting as the absence of explicitness, consider that Murphy's (2001) Missing Mittens book presented the sequence 1, 2, 3, 4, 5 .. but talked about these quantities without using the word "count" as the excerpt in Table 2 illustrates.

\section{Rationality}

The rationality dimension identifies how explicitly the pictures might draw a reader's attention to changes in the terms of a sequence. We initially used the dichotomous theoretical lens of rote and rational counting (Rea \& Reys, 1970) to analyze whether counting books exclusively provided a numeral or number word sequence or whether such written symbols were supported with pictorial representations. We expected that if an author presented numerals in a skip counting sequence the 
Table 2. Definitions and examples of explicitness types.

\begin{tabular}{|c|c|c|c|c|}
\hline $\begin{array}{l}\text { Category } \\
\text { Terms }\end{array}$ & Code & Definitions & Data Examples & Citation \\
\hline $\begin{array}{l}\text { Explicit } \\
\text { Scalar }\end{array}$ & ES & $\begin{array}{l}\text { Text explicitly identified to the reader the scalar } \\
\text { by which the sequence counted (e.g., "by } \\
\text { fives"). }\end{array}$ & $\begin{array}{l}\text { "This book counts by twos." (p. 1) } \\
\text { "You can get to } 100 \text { counting by } 5 \text { s." (p. 7) }\end{array}$ & $\begin{array}{r}\text { Pallotta } \\
(2005) \\
\text { Franco } \\
(2002)\end{array}$ \\
\hline $\begin{array}{l}\text { Explicit } \\
\text { Counting }\end{array}$ & EC & $\begin{array}{l}\text { In either the title or at least twice in the text, } \\
\text { book stated to "count" or that the sequence } \\
\text { was "counting," but did not explicitly state } \\
\text { a scalar. }\end{array}$ & $\begin{array}{l}\text { "You can count cereal. What fun it will be! See } \\
\text { one." (p. 1) }\end{array}$ & $\begin{array}{r}\text { McGrath } \\
\text { (1998) }\end{array}$ \\
\hline $\begin{array}{l}\text { Implicit } \\
\text { Counting }\end{array}$ & IC & $\begin{array}{l}\text { Text never used the word "count" to inform the } \\
\text { reader that the sequence was a counting } \\
\text { sequence. }\end{array}$ & $\begin{array}{l}\text { "Only three odd mittens- they couldn't find one } \\
\text { more. Any cow needs more than three; she } \\
\text { needs an even four... Billy looked and found } \\
5 \text { mittens, but they really needed six." (p. 12, } \\
\text { p. 16) }\end{array}$ & $\begin{array}{l}\text { Murphy } \\
\text { (2001) }\end{array}$ \\
\hline
\end{tabular}

illustrations would also convey this idea. Rational representations of number, however, were not synonymous with rational representations of sequences, so we disaggregated the rational counting category to Rational Counting Sequence (RS) and Rational Counting Terms (RT). Pictures in an RS counting book portrayed every term in the sequence in a way that accentuated for the reader the scalar used in the sequence. An RT counting book provides a picture that conveys meaning about each number; however, it fails to highlight the pattern of the stated sequence the way an RS book does. To clarify these distinctions, operationalized definitions follow along with examples from each type.

- Rational Counting Sequence (RS): Images represent each term of the sequence organized or grouped to specify the scalar of the stated sequence.

- Rational Counting Terms (RT): Images represent the numeral or number word shown in each term of the sequence, but images and organization of those images do not specify the scalar pattern of the stated sequence.

- Rote Counting (RC): Numerals and/or number word counting sequences shown without images.

To clarify these definitions, whole number counting sequences are discussed first followed by examples of sequences that counted by a scalar other than one to reflect skip counting.

\section{Sequences with scalar of one}

An example of a Rote Counting Book (RC) was Chicka Chicka 123 (Martin et al., 2004), which provided only sequences of numerals, but the pictures did not provide meaning for the written numerals. In contrast, an example of a Rational Counting Terms (RT) counting book was Curious George Learns to Count from 1 to 100 (Rey, 2005) because it included a visual representation for every numeral from 1 to 100 using a different type of object, person or animal. Consider that drawings of 29 people with 58 waving hands accurately represented 58 . On the next page, the illustrator accurately showed 59 with 59 wheels on various modes of transportation such as wheel chairs, skate boards, bicycles with and without training wheels, etc. (Rey, 2005). Thus, the difference between the terms of the sequence from 58 to 59 objects would be difficult to compare. Consequently, in terms of communicating the $n+1$ relationship from one number to the next (Le Corre \& Carey, 2008), the pictorial representations might not help children develop this meaning. In contrast, The MઐM's Counting Book (McGrath, 1994) used the same objects for each number in the sequence and also organized a pictorial representation of each number from one to twelve in a linear arrangement. Therefore, The M\&M's Counting Book pictorially represented each term of the sequence in a way that highlighted the $n+1$ pattern of the sequence, making it an RS book. 


\section{Sequences with scalars greater than one}

Next we provide examples of Rational Counting Terms and Rational Sequence for books that skip counted.

Rational counting terms. If the images never or only sometimes represented changes in the terms of a sequence, these were Rational Counting Terms books. The Crayon Counting Book (Ryan \& Pallotta, 1996) and Eating Pairs (Schuette, 2003) illustrate this category.

Each page of The Crayon Counting Book (Ryan \& Pallotta, 1996) counted by two to explain even numbers from 0 to 24 , followed by odd numbers from 1 to 23. Most numbers were pictorially represented with distinct crayons a child could count. Although each page showed a numeral two greater or less than the previous page, the book never visually paired the crayons to illustrate the addition or reduction of two crayons, so this was an RT book.

Eating Pairs (Schuette, 2003) provided paired visual representations for 2, 4, 6, 8, 10, 12, 14, 16, 18, and 20 fruits and vegetables, with each number on its own page. As discussed in the Counting Sequence Type section, the next number shown after 20 was 100 . The 100 peas were not arranged in groups of two or any other consistent grouping. Thus, the visual representation failed to continue to communicate the concept of pairs promised in the title: Eating Pairs. For this reason, this was an example of an RT counting book.

Rational sequence. How Many Ants? (Brimner, 1997) was an RS book because it increased the number of ants on each page by 10, which the illustrator emphasized by keeping the new ants separated from the prior total of marching ants. Missing Mittens (Murphy, 2001) was also an RS book because it represented every number in the sequence with arrays of mittens as well as dotted outlines to emphasize a mitten that was missing from the pair.

\section{Discussion}

Regardless of whether children's books are informational texts, stories written to teach math, or true literature without the intention to teach math (Shih \& Giorgis, 2004), we defined any books with at least two instances of number in the text as number-related books. A number-related book could provide opportunities for children to think about quantities by counting objects, subitizing, using a number sequence, or thinking about quantities in other ways. We operationalized definitions of books that, at least to some extent, count for children as a distinct subset, which we named counting books. In other words, in contrast to prior uses of the terms, counting books are more than a synonym for number-related books.

Using the book as the unit of analysis, we categorized and described how arithmetic sequences were portrayed in counting books. Next, we discuss potential learning affordances and issues for the book types identified along each dimension of the typology in relation to a) the mathematics content such types reflect and b) prior research of children's number books.

\section{Types in relation to mathematics content standards and prior children's book research}

The conceptual typology developed here yielded three dimensions useful for categorizing children's counting books: counting sequence type, explicitness of counting, and rationality.

\section{Counting sequences}

The two prior studies on the mathematics content of children's books about number coded and quantified limited aspects of counting sequences: whether numbers were presented sequentially and which scalars a book used (Powell \& Nurnberger-Haag, 2015; Ward et al., 2017). To move beyond percentages to focus on qualitative characteristics, the counting sequences dimension of the typology delineated here afforded insight as to how books portrayed these arithmetic 
sequences. The distinctions among the seven accurate counting sequence types, in addition to identifying an inaccurate type, are important findings of this study. This typology provided a more nuanced lens to think about how children, through their books, might learn arithmetic sequences as part of their developing sense of number. For example, Ward et al. (2017) reported that if a book skip counted, 10 was the most common skip-count value. Most researchers and educators, including ourselves at first, might think these sequences would be presented as the simplest type in which 10 is the initial value (i.e., 10, 20, 30, etc.) or because children's books tend to repeat ideas, another way books might skip count by 10 is to repeat this same simple sequence multiple times in different contexts. These two ways are reflected by the types we identified as Skip Counts (SC) and Multiple Different Scalars (MDS), respectively. However, this study found a scalar of 10 (or any other scalar) could be presented in five accurate and nuanced ways. Each of these nuanced ways relate to important ways elementary children need to develop ideas of number.

Skip counting is a valid way to count. The four accurate skip counting book sequence types (Skip Counting-SC, Multiple Different Scalar-MDS, Different scalar to the Same Value-DSV, and Same scalar Different Value-SDV) have the potential affordance of communicating to children that skip counting is also a valid way to count. The need for children to master these ideas is implied through standards of skip counting skills in the U.S. in kindergarten (count by 10) and second grade ( $2 \mathrm{~s}, 5 \mathrm{~s}$, $10 \mathrm{~s}$, and $100 \mathrm{~s}$ ) (National Governors Association Center for Best Practices \& Council of Chief State School Officers, 2010, pp. 11, 19). Because children as young as kindergarten are expected to have mastered skip counting by 10, any SC, MDS, DSV, or SDV counting books that use a scalar of 10 could be used with those children who rationally count by ones to recognize that skip counting is a valid way to count.

Count on from any value by skip counting. To flexibly add and subtract in ways that reflect number sense, children need to be able to count on from some value with a scalar other than one. For instance, children need to count by 10 from different initial values (as portrayed in SDV counting books), such as if starting at 18 and counting on 30 more (e.g., " $18,28,38,48$ ").

The skip count value can differ from the numbers stated. By counting on from any value, these books also imply that the skip count value can differ from the stated numbers. Books that use a scalar of 10 or 100 might provide learning experiences to represent the mathematical ideas required in 1.OA.1 to mentally add 10 or 100 to any number (National Governors Association Center for Best Practices \& Council of Chief State School Officers, 2010, p. 19).

The skip count value can change while counting. Only the MWS book type could support children to develop an understanding that it is acceptable to change the skip count value flexibly to accomplish a goal, such as when counting money or minutes. Such books may provide a foundation of counting that could support children prior to mastery of 2.MD.7-8 in which they need to count money (National Governors Association Center for Best Practices \& Council of Chief State School Officers, 2010, p. 20).

Base-ten number development. Children learning to skip count by 10 through any of the accurate counting sequence book types with a scalar of 10 would expose children to some foundations of baseten number patterns. To provide experiences in which children begin to think about "skip-counting by place value parts" as described in Battista (2012, p. 7), Same Scalar Different Value counting books that have a scalar of 10 may best represent the mathematical idea. Such books would show multiple examples of counting by 10 in various ways such that at most one sequence would include decade numbers. 
MNS books may teach children inaccurate ideas about counting. The approach of prior research to report presence of skip counting (e.g., skip counts by 10) and sequencing (i.e., shown in or out of sequence) as separate characteristics of a book (see Powell \& Nurnberger-Haag, 2015; Ward et al., 2017) may mislead stakeholders. Researchers or consumers such as teachers and parents who wish to teach children to count by 10 , might assume a book identified as skip counting by 10 would be beneficial. On the contrary, the problematic Multiple Scalars No Scenario (MNS) counting books, in which readers would see numerals written as “ .. 7, 8, 9, 10, 20, $30 \ldots$ ” switched scalars to count by 10. It seemed as if authors of MNS book types manufactured a way to include the numbers 0 or 100 even if this might mistakenly imply to young readers that 0 or 100 is the next counting number after 20 , 50 , or some other inaccurate value. Ward and colleagues found that "the 'out of sequence' number was always greater than 10" (Ward et al., 2017, p. 54). Thus, the current analysis qualifies the recommendations in our first study (Powell \& Nurnberger-Haag, 2015) in which we called for more books to include numbers greater than 20 as well as specifically 0 and 100 . When we made this recommendation, we assumed all number sequences presented in children's books would be accurate. The current findings, however, revealed the need to specify accuracy as a criterion. The sequences of numbers used should be accurate if lifted from the context (i.e., simply listed in the presented order as book types: WC, OS, SC, MDS, DSV, SDV) or the context of the story should make the numerical sequence reasonable (MWS). The counting sequence types identified in this typology provide ways to proactively recognize and address this issue.

\section{Explicitness}

How we used the term explicitness warrants clarification compared to prior research. Van Den Heuvel-panhuizen and Elia (2012) used the dichotomous terms explicit mathematics or implicit mathematics to refer to whether a book was about mathematics. In Powell and Nurnberger-Haag's study of number-related books (Powell \& Nurnberger-Haag, 2015), the term explicit was used at the page level specifically related to number with the term explicit counting, similar to Ward et al. (2017), to identify whether the author labeled each object with a numeral or number word. In this study, we use explicitness at the book level. Irrespective of the specific scalar used, the explicitness dimension reflects the degree to which the words communicated the counting process. Whether the books children read tell them, "let's count by twos" (ES) or "let's count" (EC), or avoid the word "count" (IC), there are potentially different implications for what a student might notice or generalize about valid ways to count. Consider that limited examples of triangles (i.e., primarily equilateral and acuteisosceles) has impeded children's acceptance of other triangles as real triangles (Schifter, 1999). Similarly, children spend their first years of life learning to count. During those first years the only correct way to count is to state the natural numbers in order (i.e., $1,2,3, \ldots$ ). Would a predominance of IC books lead children to believe number sequences that skip count by two, five, or 10 are not real counting, whereas ES or EC types facilitate a broader generalization of what it means to count?

\section{Rationality}

The dimension of rationality is important to consider when books are used to teach children to count objects (e.g., National Governors Association Center for Best Practices \& Council of Chief State School Officers, 2010, K.CC., pp. 4-5). Prior studies reported descriptive statistics of whether images were shown to represent each numeral or number word and whether the same or different objects were shown throughout the book (Powell \& Nurnberger-Haag, 2015; Ward et al., 2017). To label these ideas in the current study we adopted the dichotomous terms used to describe how children count (i.e., rational counting and rote counting; Rea \& Reys, 1970). Moreover we extended this theoretical framing to an ordinal dimension to identify a level above rational counting. Thus, the rationality dimension in the current study better specifies how explicitly the images portray the meaning of the mathematical idea. Books that simply state numerals or number words without images are conceived of as rote counting (RC), because such characteristics could only support children's growth of rote counting skills (such as in the U.S. standards K.CC.1 or 2.NBT.2). However, these books would fail to support 
understanding of counting objects in the ways specified in K.CC.4-5 or 2.OA.3. Rational Counting Term books may focus more on real-life contexts that lend themselves to mathematizing, such as Curious George Learns to Count from 1 to 100 (Rey, 2005) in which the illustrations reflect the ways quantities of objects are usually seen. In contrast, Rational Counting Sequence books may draw attention to the complexities of the mathematics, because this type provides the most explicit visual support to aide children to understand the numbers within the sequence as well as the patterns of the sequence. To what each of these book types draw readers' attention could have differing implications for various learners in light of Felton's (2010) explanation about how students may focus on the mathematical context or the mathematical concept.

\section{Interaction of dimensions in terms of diverse theories of learning}

A strength of a conceptual typology is that because it describes an empirically analyzed phenomenon without adherence to a particular theory it is possible for varied theoretical perspectives to use the same "scientific shorthand" to advance an area of research (Collier et al., 2012; Ragin, 1987, p. 149, as cited in Delbridge \& Fiss, 2013). The block structure visualization of the typology in Figure 2 along with the terms and definitions for each type in the Findings section provide this scientific shorthand (Counting Sequence-Explicitness-Rationality) as a foundation for future research about children's learning with counting books.

Due to the common learning theories upon which mathematics education researchers draw (e.g., constructivism, situated cognition, critical theory, etc.) and potential learning trajectories (e.g., Sarama \& Clements, 2009), mathematics education research tends to view as a system the complexities of what children already know in relation to their learning experiences. In contrast, cognitive development and cognitive psychology researchers tend to design experiments to isolate factors they can explain using theories of or referring to mechanisms of attention, pattern recognition, categorization, and so forth. With these diverse research approaches in mind, we pose some potential hypotheses or areas of investigation to illuminate how varied disciplines could use the counting book typology to further advance research on learning mathematics with children's books. We also provided more detailed

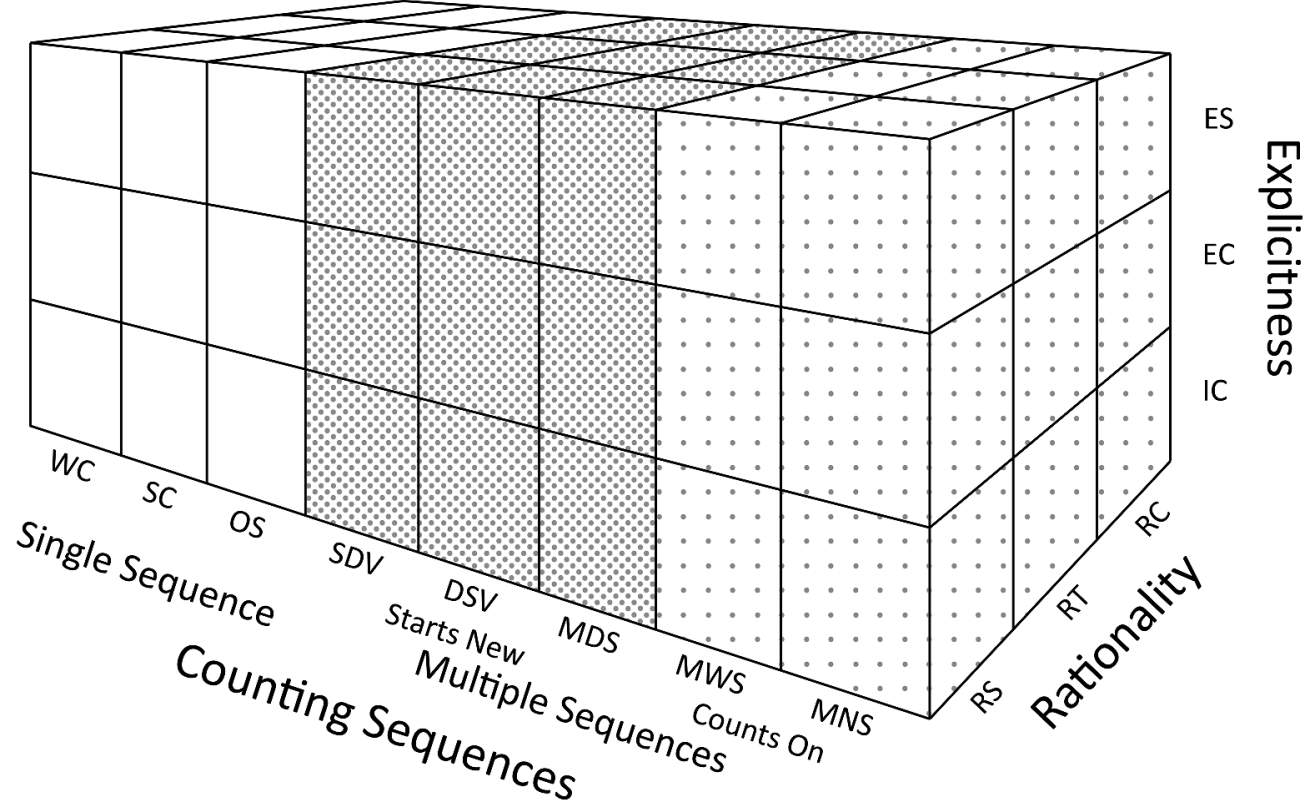

Figure 2. Counting book typology in three dimensions: counting sequence, explicitness, and rationality. 
design suggestions in the on-line Appendix B to encourage researchers to investigate these important avenues.

\section{Learning affordances of counting books compared to other number-related books}

This article provided operationalized definitions for counting books as a subset of number-related books. Studies about the relative learning affordances of these category types are needed. For example, using the methodological approach of R. L. Hojnoski et al. (2014) and R. Hojnoski (2016) research could assess the question: Which books (counting books, number-related non-counting books, or books that are not number-related) foster more numerical talk generally as well as specifically related to each counting principle? Such a question would be valuable given that many educators or caregivers use the images to emphasize or encourage children to practice counting even if the book is not a number-related book (Anderson et al., 2004). In fact, under certain conditions children have learned more about counting with books than by using manipulatives (Petersen et al., 2014). If recommendations to use such books more frequently are heeded, then nuances we identified in this study will become even more important to ensure books selected in formal and informal learning environments could foster learning.

A necessary focus of future research is to understand how each of the book types influences children's understanding of cardinality. Prior psychology research, rooted in theories of attention, experimentally compared researcher created books that named the cardinality of a set for children before counting rather than counting first and then naming the cardinality (Mix et al., 2012). Stating the cardinality first facilitated preschoolers to become cardinality-knowers (Mix et al., 2012; Petersen et al., 2014). This led us to hypothesize that publicly available children's books that are number-related but not counting books might better facilitate children to become cardinality-knowers. In light of our study, consider that the structure of a WC counting book provides the predictable rote sequence, so child readers may accurately state the next number word while ignoring the visual quantity of the represented set. Such a research question using typical methodologies in mathematics education might be: In what ways do number-related non-counting books and Whole Number Counting (WC) book types each support children's development of cardinality? Whereas, an experimental research question might ask: Which book type better helps children become cardinality knowers?

\section{Learning affordances with accurate counting book types}

Research is needed to uncover learning affordances of the seven accurate counting sequence types in relation to how explicitly the images and words portray those types. Next we discuss the importance of studying effects on learning with these specific types using varied theoretical perspectives.

Nuances of ways scalars and values were shown in multiple sequences. Researchers from varied theoretical perspectives might make different predictions about which book types provide better learning opportunities. An example of a potential focus would be the two counting sequence types that are most nuanced from each other: Different Scalar Same Value (DSV) and Same Scalar Different Value (SDV). The DSV type focuses on a particular number, which reveals to readers that multiple scalars can form that number. In contrast, the SDV type focuses reader's attention on the scalar, which reveals to readers that just because one knows the scalar, does not mean the same sequence of numbers will be shown.

Typically, cognitive development or cognitive psychology research experimentally compares phenomena to determine optimal resources and understand mechanisms for learning by limiting as many variables as possible. Thus, if interested in understanding whether DSV or SDV books are better for learning particular content such as skip counting, factors, multiples, and so forth, such researchers might use the typology to hold constant the rationality and explicitness dimensions in their experimental design. Based on research on attention and cognitive load that more explicit and less irrelevant information focuses attention to increase saliency and leads to greater learning outcomes (Eng et al., 2018; Fisher et al., 2014), such researchers might 
randomly assign children to read DSV-ES-RS or SDV-ES-RS counting books and compare pre and post knowledge of counting sequences. In summary, the Counting Book Typology provides categorizations that could assist experimental researchers to select a sample of books that eliminates or at least limits variability.

Mathematics education researchers who draw on radical constructivist theories of learning (Kamii et al., 2005; Von Glasersfeld, 1991) might predict the explicitness and rationality dimensions that provide the most opportunity for children to construct their own knowledge might offer the richest learning and opportunity for diverse thinking to be observed. In other words, they might select IC-RC books as the best types of DSV and SDV books, because these are the least instructive. From a situative perspective (Anderson \& Gold, 2006; Lave \& Wenger, 1991), a researcher might select ES-RS books to investigate how a learner engages with the specific characteristics of selected books as part of the situated context (i.e., other aspects of the learning context such as peers, adults, and physical environment). The situatedness of the learning tool (i.e., the book) may be emphasized through qualitative analyses about the particular context of the text with regard to the explicitness of the image groupings (RS) and the explicitness of language about counting (ES).

\section{Implications for learning with an inaccurate counting book type}

Children have learned inaccurate information in their books about science (Mayer, 1995; Rice, 2002); shape-related books have been found to teach the inaccurate and incomplete ideas documented in children's as well as adults' thinking (Nurnberger-Haag, 2017), and small differences can matter (Petersen et al., 2014). Thus, even seemingly small explicit or implicit inaccuracies of counting books could negatively impact children who read and repeatedly reread such books. Ethically, however, we discourage introducing the inaccurate MNS type to children simply for research.

\section{Broader research foci to clarify impact of dimensions}

Another important implication is that the Counting Book Typology could contribute to researching equity, social justice, and/or identity if viewed through broader theoretical perspectives to understand experiences and impact on learning with counting books.

\section{Capitalizing on play}

Studies that use theories of play as a lens with which to notice mathematical thinking in playbased preschool or kindergarten classrooms (e.g., Wager \& Parks, 2014), might benefit from this typology in at least two ways. First, the typology could help researchers better recognize which book types to offer to extend the mathematical ideas children naturally use in their play. Second, the counting book typology is one tool to identify mathematical and explicitness features of the books, which researchers could use to investigate why and how children might replicate or use ideas from certain books in their play.

\section{Contribute to social justice in terms of socioeconomic status}

Parents with less education are more likely to read counting books at home to help their preschool children learn numerical ideas (Gaylord et al, 2020). In other words, how frequently parents read counting books with their preschool children and level of parental education are inversely correlated (Gaylord et al., 2020). Moreover, prior to school mathematics achievement is a strong predictor of overall achievement many years later (Claessens \& Engel, 2013), so given that education is correlated with income, our study punctuates the need to investigate the quality of counting books, which could have the greatest impact on children in lower-income homes. 


\section{Contribute to social justice in terms of ability, gender, race, ethnicity, and identity}

Children's books are selected for multiple complex reasons beyond mathematics. For example, a book might seem particularly appealing if its characters better reflect the children with whom teachers or researchers are working. Whether these books serve as mirrors for children to see themselves reflected or windows for children to see their peers (Gutiérrez, 2007), if children read books with inaccurate or questionable mathematics, might this unintentionally replicate or further entrench already existing inequities these book choices were intended to change (Nurnberger-Haag et al., 2019)? Children's books in general have been evaluated using affect valuation theory to investigate how books differentially portray expressions of emotions by characters of different races or ethnicities (Grady et al., 2018). This inspires questions such as how, if at all, are children of varied diversities represented in accurate and inaccurate counting book types? In accurate counting book types, who is portrayed as doing simple or more complex mathematics? This typology could provide a conceptual tool for analyzing the children's books in relation to Critical Theory (e.g., Taylor et al., 2009) or other theoretical approaches that address identity or other perspectives on social justice to ensure all learners meet their potential and see themselves as doers of mathematics (Wernet \& Nurnberger-Haag, 2015).

\section{Conclusions}

Rather than categorizing a children's book by what a child could do with it, the current study documented characteristics of books themselves. What children, families, and teachers do with such books and how children learn is crucial to uncover. Claims about what children learn with books, however, should come after or along with specifying the mathematics in the books implemented in such studies (Nurnberger-Haag, 2017; Yilmaz Genc et al., 2017). This, however, has not yet been the case. Resources used in classrooms are curricular resources, irrespective of whether these were designed for classroom learning (e.g., textbooks) or these are children's books used in formal and informal learning spaces. Hence, regardless of the type of resource, if studies identify mathematics learning effects of curricular resources, the field's standards for reporting the characteristics of the mathematics and instructional approaches used that led to these outcomes should be similarly transparent. This study aimed to provide a tool for researchers to report such characteristics of counting books.

\section{Mathematics in children's books should matter}

Researchers and practitioners need guides to notice salient aspects of children's mathematicsrelated books (Cotti \& Schiro, 2004; Nesmith \& Cooper, 2010; Van Den Heuvel-panhuizen \& Elia, 2012). The Counting Book Typology offers such a guide for a particular subset of numberrelated books. Such objective criteria should be the primary filter for selecting books to teach children mathematics (Nurnberger-Haag, 2017, 2018b; Yilmaz Genc et al., 2017), rather than averaging mathematical quality with other ratings, such as engagement factors, as was common in existing tools (e.g., Hellwig et al., 2000, p. 139; Hunsader, 2004; Van Den Heuvel-panhuizen \& Elia, 2012). This is especially important given that psychology research revealed a tension between such engagement factors and learning outcomes (Fisher et al., 2014).

\section{Research tools should be objective and broadly comprehensible for varied stakeholders}

Research must specify how to determine the quality of mathematics in books to aide educational researchers and practitioners who may not have strong mathematics backgrounds as well as to assist those who know mathematics well. Prior tools have relied on Likert judgments of accuracy (e.g., Hellwig et al., 2000) or broad and subjective criteria such as mathematical scope (i.e., "make understanding possible at different levels, offer multiple layers of meaning, and anticipate future concept development"; van den Heuvel-panhuizen \& Elia, 2012, p. 34). Such tools leave too much room for individual interpretation such that ratings depended on each rater's mathematical as well as 
pedagogical knowledge (Nesmith \& Cooper, 2010). In contrast, this typology offers objective definitions of each type and subtype that may support stakeholders with a range of pedagogical and mathematical knowledge to critique counting books. We encourage researchers to investigate for which, if any, stakeholders this may be true such as daycare providers, parents, elementary educators, librarians, researchers, publishers and authors. To change the books produced, researchers must also advocate in venues where the target stakeholders are the audience (i.e., targeted professional organizations, social networking, etc.).

\section{Research tools for mathematics learning with books need rigorous development}

Many research articles about learning mathematics with children's books have relied on rubrics written for teachers that were based on practical experience without meticulous empirical development. In contrast, the research framework Learning-Supportive Characteristics of Picturebooks for Learning Mathematics, which was intended to apply to any mathematical domain, used a rigorous method to establish expert opinion of the framework (van den Heuvel-panhuizen \& Elia, 2012). Yet, a methodological limitation was that only three books were used to create that framework without subsequent replication or validation with other books. Moreover, the three books used omitted the Number and Operations domain. Because the mathematics of children's books varies tremendously across as well as within each content domain (Nurnberger-Haag, 2017; Powell \& Nurnberger-Haag, 2015; Yilmaz Genc et al., 2017), a methodological strength of the current study was the focus on a 65book subset of the number and operations domain with additional validation using 126 books from the same domain.

\section{Contributions of counting book typology as a methodological tool}

Typologies are useful "to establish an appropriate set of cases for study" as a foundation for research designs and provide insights to "synthesize conclusions" in qualitative as well as quantitative research (Collier et al., 2012, p. 228). Moreover, even if typologies were not consulted at the onset of a quantitative study design, during analysis typologies can reveal underlying reasons for and suggest ways to "overcome an impasse in statistical analysis" (Collier et al., 2012, p. 228). How the Counting Book Typology could contribute in these ways to future research about books used for mathematics learning is summarized next (see Appendix B in the online supplementary material for detailed study ideas).

\section{Appropriate set of cases for study}

The Counting Book Typology provides guidelines to identify cases for future research investigations. Each cell of the typology could constitute a case to determine how students learn with a particular book type specified by three dimensions. Moreover, researchers' varied theoretical lenses and methodological approaches might lead them to see varying cross-sections of the typology (see Figure 2) as cases to investigate.

\section{Synthesize conclusions}

The Counting Book Typology could aide synthesis of conclusions in both quantitative and qualitative studies. Psychology-based articles typically report multiple experiments about the same phenomenon in order to isolate variables and synthesize conclusions. Thus, this typology could aide such validation within or across counting sequence book types. Yet, the need to synthesize conclusions might be even more important with qualitative research methods more common in mathematics education. By this we mean that the typology could improve how well learning contexts are described. Rather than only characterizing students and teacher interactions with books at a general level such as topic, alignment with standards, or specifics that are 
idiosyncratic to the particular book(s), the typology could aid a middle level description of the books to more richly describe the complex learning context with greater potential transferability.

\section{Overcome a statistical impasse}

Without proper classification (Collier et al., 2012; Niknazar \& Bourgault, 2017) statistical analyses of what children learn from number-related books may yield uninterpretable or misinterpreted results due to a lack of understanding about the specific characteristics of the books. To design experimental studies that might avoid statistical impasses or to reinterpret results of existing data when an impasse occurs (Collier et al., 2012), the Counting Book Typology could serve as a tool. These distinctions might also aid researchers to appropriately report what a study was able to compare even if this differed from the original intent of the study. This transparency of interpretations as to which counting books such findings might generalize are crucial for research validity.

\section{Practical implications}

Ethically we believe it is important to create research tools that are cognizant of practice and require little translation for teachers to use. The counting book typology was developed with the idea in mind that typologies are "useful tools for both researchers and practitioners" (Delbridge \& Fiss, 2013, p. 329). Although teachers prefer specific title recommendations, the purpose of the current study was to provide a conceptual tool to analyze current counting books as well as those published in the future. An approach teacher educators could use to make this tool comprehensible is to suggest that in-service teachers (ISTs) or pre-service teachers (PSTs) imagine the block structure of the typology in Figure 2 as a display of crates or shelves of counting books within a larger number-related category area of a library. Each crate holds a specific type of counting book based on the three dimensions of counting sequence, explicitness and rationality. We encourage our mathematics teacher educator (MTE) colleagues to help ISTs and PSTs learn how to critically evaluate the mathematics of a children's book to determine how, if at all, to use it with students (Nurnberger-Haag, 2018b).

It will most likely be several years before ISTs learn of results from any suggested research studies. Therefore, our best practical advice for MTEs who advise ISTs and families on early mathematics resources would be to gather collections of books that include a range of number-related-noncounting books as well as the accurate and explicit counting book types, meaning Explicit ScalarRational Sequence types of each of the following counting sequence types (WC, SC, OS, SDV, DSV, MDS, MWS). Consistent with recommendations for using imperfect books for other mathematical domains (Nurnberger-Haag, 2017, 2018b; Nurnberger-Haag et al., 2019), we suggest that the inaccurate MNS books only be used by educators in targeted lessons that ask children to collectively critique and make sense of how the authors counted.

\section{Multiple tools needed to advance mathematics learning with children's books}

Multiple research teams from diverse theoretical stances are needed to investigate the mathematicsrelated books themselves and how such books influence learning. Yet, some impediments to advancing understanding about a phenomenon across disciplinary boundaries are adherence to particular theories and methods, disciplinary terms, and citing primarily within one's own discipline (Norton \& Nurnberger-Haag, 2018). The counting book typology provides a conceptual tool meant to serve diverse theories and research methods while providing a common set of terms. We delineated many research questions here and in the online supplementary material with the intent to inspire researchers to tackle these issues. Moreover, we hope this tool illuminates additional questions to pursue that would have otherwise remained unexplored. Furthermore, additional content-domain specific (e.g., 
number and operations, geometry, measurement, etc.) conceptual tools such as frameworks, taxonomies, and typologies need to be developed to move this emerging area of research forward.

\section{Funding}

The analysis was supported in part by start-up funds Kent State University awarded to Julie Nurnberger-Haag.

\section{Notes on contributors}

Julie Nurnberger-Haag has been a mathematics educator for 25 years and is currently an Assistant Professor of mathematics education in the School of Teaching, Learning \& Curriculum Studies at Kent State University. For seven years she was a mathematics teacher and instructional coordinator at a 1st-12th school for students with learning differences and has worked with teachers and librarians for mathematics professional development. In her current position she is a mathematics teacher educator and conducts research on the mathematical accuracy, affordances, and issues with resources used to teach mathematics, so that we can design better learning experiences for people from birth through adulthood. This research focus includes analysis of informal resources such as children's books and formal resources designed for classrooms such as manipulatives, games, and other instructional tools.

Anita N. Alexander is currently an Assistant Professor at the University of Bilkent in Turkey. She is a mathematics educator and researcher with over 15 years of teaching experience at the high school and college levels. Her primary research objective is to improve undergraduate mathematics education by implementing inquiry-based learning to promote a conceptual understanding of essential concepts. Her research includes examining teaching norms at the high school and undergraduate level. She also collaborates on research for early childhood mathematics education with the overarching objective of vertical alignment. At the time this study was conducted, she was a doctoral student at Kent State University.

Sarah R. Powell is an Associate Professor in the Department of Special Education at the University of Texas at Austin. Her teaching and research focus on mathematics and students experiencing learning difficulties. Powell currently conducts school-based research projects from preschool to middle school funded by the Institute of Education Sciences, National Science Foundation, Office of Special Education Programs, Office of Innovation and Improvement, Texas Education Agency, and T.L.L. Temple Foundation.

\section{References}

Anderson, A., Anderson, J., \& Shapiro, J. (2004). Mathematical discourse in shared storybook reading. Journal for Research in Mathematics Education, 35(1), 5-33. https://doi.org/10.2307/30034801

Anderson, D. D., \& Gold, E. (2006). Home to school: Numeracy practices and mathematical identities. Mathematical Thinking and Learning, 8(3), 261-286. https://doi.org/10.1207/s15327833mt10803_4

Ayres, L., \& Knafl, K. (2008). Typological analysis. In L. M. Given (Ed.), The Sage encyclopedia of qualitative research methods, vol. 2, p.900-901. Sage Publications. https://doi.org/10.4135/9781412963909.n472

Ball, D. L. (1992). Magical hopes: Manipulatives and the reform of math education. American Educator, 16(2), 14-18, 46-47. https://www.aft.org/sites/default/files/periodicals/ae_summer1992_ball.pdf

Baroody, A. J., Eiland, M., \& Thompson, B. (2009). Fostering at-risk preschoolers' number sense. Early Education and Development, 20(1), 80-128. https://doi.org/10.1080/10409280802206619

Battista, M. T. (2012). Cognition-based assessment \& teaching of place value: Building on students' reasoning. Heinemann.

Book Industry Study Group. (2016, October 1). Juvenile nonfiction. JNF013030 JUVENILE NONFICTION/concepts/ counting \& numbers. In BISAC subject headings list, Juvenile nonfiction. Retrieved from http://bisg.org/page/ JuvenileNonfiction Oct 1, 2016

Brimner, L. D. (1997). How many ants? Scholastic.

Brooks, N., Pogue, A., \& Barner, D. (2011). Piecing together numerical language: Children's use of default units in early counting and quantification. Developmental Science, 14(1), 44-57. https://doi.org/10.1111/j.1467-7687.2010.00954.x

Campbell, P. F., Rust, A. H., Nishio, M., DePiper, J. N., Smith, T. M., Frank, T. J., ... Choi, Y. (2014). The relationship between teachers' mathematical content and pedagogical knowledge, teachers' perceptions, and student achievement. Journal for Research in Mathematics Education, 45(4), 419-459. https://doi.org/10.5951/jresematheduc.45.4.0419

Claessens, A., \& Engel, M. (2013). How important is where you start? Early mathematics knowledge and later school success. Teachers College Record, 115(6), 1-29 https://www.tcrecord.org/content.asp?contentid=16980.

Collier, D., LaPorte, J., \& Seawright, J. (2012). Putting typologies to work: Concept formation, measurement, and analytic rigor. Political Research Quarterly, 65(1), 217-232. https://doi.org/10.1177/1065912912437162 
Cotti, R., \& Schiro, M. (2004). Connecting teacher beliefs to the use of children's literature in the teaching of mathematics. Journal of Mathematics Teacher Education, 7(4), 329-356. https://doi.org/10.1007/s10857-004-1787-z

Dahl, M. (2005). Lots of ladybugs! Counting by fives. Minneapolis, MN: Picture Window Books.

Delbridge, R., \& Fiss, P. C. (Eds.). (2013). Editors' comments: Styles of theorizing and the social organization of knowledge. Academy of Management Review, 38(3), 325-331. https://doi.org/10.5465/amr.2013.0085

Ellis, A. B. (2007). A taxonomy for categorizing generalizations: Generalizing actions and reflection generalizations. The Journal of the Learning Sciences, 16(2), 221-262. https://doi.org/10.1080/10508400701193705

Eng, C. M., Godwin, K. E., Boyle, K. A., \& Fisher, A. V. (2018). Effects of illustration details on attention and comprehension in beginning readers, 336-341; C. Kalish, M. A. Rau, X. Zhu, T. T. Rogers (Eds.) In Proceedings of the 40th annual meeting of the cognitive science society. Cognitive Science Society. https://dblp.org/db/conf/cogsci/ cogsci2018.html

Felton, M. D. (2010). Is math politically neutral. Teaching Children Mathematics, 17(2), 60-63. https://www.jstor.org/ stable/41199594

Fisher, A. V., Godwin, K. E., \& Seltman, H. (2014). Visual environment, attention allocation, and learning in young children: When too much of a good thing may be bad. Psychological Science, 25(7), 1362-1370. https://doi.org/10. $1177 / 0956797614533801$

Flevares, L. M., \& Schiff, J. R. (2014). Learning mathematics in two dimensions: A review and look ahead at teaching and learning early childhood mathematics with children's literature. Frontiers in Psychology, 5, 1-12. https://doi.org/10. 3389/fpsyg.2014.00459

Franco, B. (2002). Many ways to 100. Mankato, MN: Yellow Umbrella Books.

Frank, A. R. (1989). Counting skills-A foundation for early mathematics. The Arithmetic Teacher, 37(1), $14-17$.

Friedman, M. (1978). The manipulative materials strategy: The last pied piper? Journal for Research in Mathematics Education, 9(1), 78-80. https://doi.org/10.2307/748965

Fuson, K. C., \& Secada, W. G. (1986). Teaching children to add by counting-on with one-handed finger patterns. Cognition and Instruction, 3(3), 229-260. https://doi.org/10.1207/s1532690xci0303_5

Gaylord, S. M., Connor, D. O., Hornburg, C. B., \& McNeil, N. M. (2020). Preferences for tactile and narrative counting books across parents with different education levels. Early Childhood Research Quarterly, 50, 20-39. https://doi.org/ 10.1016/j.ecresq.2018.07.010

Gelman, R., \& Gallistel, C. R. (1978). The child's understanding of number. Harvard University Press.

Gelman, R., \& Meck, E. (1983). Preschoolers' counting: Principles before skill. Cognition, 13(3), 343-359. https://doi.org/ 10.1016/0010-0277(83)90014-8

Godwin, K. E., Eng, C. M., Todaro, R., Murray, G., \& Fisher, A. V. (2018). Examination of the role of book layout, executive function, and processing speed on children's reading fluency and comprehension, 1723-1728. In Proceedings of the 40th annual meeting of the cognitive science society, C. Kalish, M. A. Rau, X. Zhu, T. T. Rogers (Eds.). Cognitive Science Society. https://dblp.org/db/conf/cogsci/cogsci2018.html

Grady, J. S., Her, M., Moreno, G., Perez, C., \& Yelinek, J. (2019). Emotions in storybooks: A comparison of storybooks that represent ethnic and racial groups in the United States. Psychology of Popular Media Culture, 8(3), 207. https:// doi.org/http://dx.doi.10.1037/ppm0000185

Gutiérrez, R. (2007). Context matters: Equity, success, and the future of mathematics education. In T. Lamberg \& L. R. Wiest (Eds.), Proceedings of the 29th annual meeting of the north american chapter of the international group for the psychology of mathematics education (pp. 1-18). University of Nevada.

Hachey, A. C. (2015). Introduction to the special issue on early childhood mathematics education. Early Education and Development, 26(3), 315-318. https://doi.org/10.1080/10409289.2015.995455

Hellwig, S. J., Monroe, E. E., \& Jacobs, J. S. (2000). Making informed choices: Selecting children's trade books for mathematics instruction. Teaching Children Mathematics, 7(3), 138-143. https://www.jstor.org/stable/41197539

Hoban, T. (1972). Count and see. New York, NY: Simon and Schuster.

Hojnoski, R., Polignano, J., \& Columba, H. L. (2016). Increasing teacher mathematical talk during shared book reading in the preschool classroom: A pilot study. Early Education and Development, 27(5), 676-691. https://doi.org/10.1080/ 10409289.2016.1102018

Hojnoski, R. L., Columba, H. L., \& Polignano, J. (2014). Embedding mathematical dialogue in parent-child shared book reading: A preliminary investigation. Early Education and Development, 25(4), 469-492. https://doi.org/10.1080/ 10409289.2013.810481

Hunsader, P. D. (2004). Mathematics trade books: Establishing their value and assessing their quality. The Reading Teacher, 57(7), 618-629. https://www.jstor.org/stable/20205408

Kamii, C. (1986). Place value: An explanation of its difficulty and educational implications for the primary grades. Journal of Research in Childhood Education, 1(2), 75-86. https://doi.org/10.1080/02568548609594909

Kamii, C., Rummelsburg, J., \& Kari, A. (2005). Teaching arithmetic to low-performing, low-SES first graders. The Journal of Mathematical Behavior, 24(1), 39-50. https://doi.org/10.1016/j.jmathb.2004.12.004

Kaufman, E. L., Lord, M. W., Reese, T. W., \& Volkmann, J. (1949). The discrimination of visual number. The American Journal of Psychology, 62(4), 498-525. https://doi.org/10.2307/1418556

Lave, J., \& Wenger, E. (1991). Situated learning: Legitimate peripheral participations. Cambridge University Press. 
Le Corre, M., \& Carey, S. (2008). Why the verbal counting principles are constructed out of representations of small sets of individuals: A reply to Gallistel. Cognition, 107(2), 2. https://doi.org/10.1016/j.cognition.2007.09.008

Lottridge, C. B. (1997). One watermelon seed. Toronto, Canada: Stoddart Kids.

Markel, M. (2009). Tyrannosaurus math. Berkeley, CA: Tricycle Press.

Marston, J. L., Muir, T., \& Livy, S. (2013). Can we really count on Frank? Teaching Children Mathematics, 19(7), 440-448. https://doi.org/10.5951/teacchilmath.19.7.0440

Martin, B., Archambault, J., \& Elhert, L. (1989). Chicka chicka boom boom. Simon \& Schuster.

Martin, B., Sampson, M., \& Ehlert, L. (2004). Chicka chicka 12 3. Scholastic.

Mayer, D. A. (1995). How can we best use children's literature in teaching science concepts? Science and Children, 32 (16-19), 43.

McDonald, J. (2007). Selecting counting books. Young Children, 62(3), 38-42.

McGrath, B. B. (1994). The M\&M's counting book. Charlesbridge Publishing.

McGrath, B. B. (1998). The Cheerios counting book. Scholastic.

Murphy, S. J. (1998b). The penny pot. New York, NY: Harper Collins.

Murphy, S. J. (1999). Henry the fourth. New York, NY: HarperCollins Publishers.

Mix, K., Sandhofer, C. M., Moore, J. A., \& Russell, C. (2012). Acquisition of the cardinal word principle: The role of input. Early Childhood Research Quarterly, 27(2), 274-283. https://doi.org/10.1016/j.ecresq.2011.10.003

Murphy, S. J. (1998). The penny pot. Harper Collins.

Murphy, S. J. (2001). Missing mittens. Harper Collins.

National Governors Association Center for Best Practices \& Council of Chief State School Officers. (2010). Common core state standards mathematics. Authors.

Nesmith, S., \& Cooper, S. (2010). Trade books in the mathematics classroom: The impact of many, varied perspectives on determinations of quality. Journal of Research in Childhood Education, 24(4), 279-297. https://doi.org/10.1080/ 02568543.2010 .510086

Niknazar, P., \& Bourgault, M. (2017). Theories for classification vs. classification as theory: Implications of classification and typology for the development of project management theories. International Journal of Project Management, 35 (2), 191-203. https://doi.org/10.1016/j.ijproman.2016.11.002

Norton, A., \& Nurnberger-Haag, J. (2018). Bridging frameworks for understanding numerical cognition. Editorial in special issue Psychology and mathematics: Bridging approaches to research for understanding the learning and teaching of number. A. Norton and J. Nurnberger-Haag (Eds.). Journal of Numerical Cognition, 411-8https://doi.org/10.5964/ jnc.v4i1.160

Nurnberger-Haag, J. (2017). A cautionary tale: How children's books (Mis)teach shapes. Early Education and Development, 28(4), 415-440. https://doi.org/10.1080/10409289.2016.1242993

Nurnberger-Haag, J. (2018a). Borrow, trade, regroup, or unpack? Revealing how instructional metaphors portray baseten number. In L. Jao \& N. Radakovic (Eds.), Transdisciplinarity in mathematics education: Blurring disciplinary boundaries (pp. 215-237). Springer International Publishing AG.

Nurnberger-Haag, J. (2018b). Follow the signs to promote accurate geometric shape knowledge: Together We can break the cycle of misinformation. Ohio Journal of School Mathematics, 80. https://library.osu.edu/ojs/index.php/OJSM/article/ view/6041

Nurnberger-Haag, J., Holford, T. L., Bryk, K. M., Strozyk, H., Harder, M., \& Davidsaver, K. (2019). A ball is not a circle: How to spot mathematical inaccuracies to improve and use shape book collections. Teacher Librarian, 1(47), 8-13.

Pallotta, J. (1991). The icky bug counting book. Watertown, MA: Charlesbridge.

Pallotta, J. (2005). Ocean counting: Odd numbers. Charlesbridge.

Petersen, L. A., McNeil, N. M., Tollaksen, A. K., Boehm, A. G., Hall, C. J., Carrazza, C., \& Devlin, B. L. (2014). Counting practice with pictures, but not objects, improves children's understanding of cardinality, pp. 2633-2638. In P. Bello, M. Guarini, M. McShane, \& B. Scassellati (Eds.), Proceedings of the 36th annual meeting of the cognitive science society. Cognitive Science Society.

Powell, S., \& Nurnberger-Haag, J. (2015). Everybody counts, but usually just to ten! A systematic analysis of number representations in children's books. Early Education and Development, 26(3), 377-398. https://doi.org/10.1080/ 10409289.2015.994466

Rauen, A. (2008). Math in our world: Counting at the Zoo. Weekly Reader Books.

Rea, R. E., \& Reys, R. E. (1970). Mathematical competencies of entering kindergarteners. Arithmetic Teacher, 17(1), 65-74. https://www.jstor.org/stable/41186128

Rey, H. A. (2005). Curious George learns to count from 1 to 100. HMH Books.

Reys, R., Lindquist, M., Lambdin, D., \& Smith, N. (2014). Helping children learn mathematics (11th ed. ed.). Wiley.

Rice, D. C. (2002). Using trade books in teaching elementary science: Facts and fallacies. The Reading Teacher, 55(6), 552-565. https://www.jstor.org/stable/20205097

Ryan, P. M., \& Pallotta, J. (1996). The crayon counting book. Charlesbridge.

Saldaña, J. (2013). The coding manual for qualitative researchers, 2nd edition. Sage Publications.

Sarama, J., \& Clements, D. H. (2009). Early childhood mathematics education research: Learning trajectories for young children. Routledge. 
Saxe, G. B. (1977). A developmental analysis of notational counting. Child Development, 48(4), 1512-1520. https://doi. org/10.2307/1128514

Scarry, R. (1975). Richard Scarry's best counting book ever. New York, NY: Sterling Publishing.

Schifter, D. (1999). Learning geometry: Some insights drawn from teacher writing. Teaching Children Mathematics, 5(6), 360-366. https://www.jstor.org/stable/41198863

Schuette, S. L. (2003). Eating pairs: Counting fruits and vegetables by twos. Capstone Press.

Shepherd, R. L. (2007). Husker numbers: A Nebraska number book. Sleeping Bear Press.

Shih, J. C., \& Giorgis, C. (2004). Building the mathematics and literature connection through children's responses. Teaching Children Mathematics, 10(6), 328-333. https://www.jstor.org/stable/41199788

Sloat, T. (1991). From one to one hundred. New York, NY: Scholastic.

Smith, K. B. (2002). Typologies, taxonomies, and the benefits of policy classification. Policy Studies Journal, 30(3), 379-395. https://doi.org/10.1111/j.1541-0072.2002.tb02153.x

Steffe, L. P. (1983). Children's algorithms as schemes. Educational Studies in Mathematics, 14(2), 109-125. https://doi. org/10.1007/bf00303681

Steffe, L. P., Cobb, P., \& von Glasersfeld, E. (1988). Construction of arithmetical meanings and procedures. SpringerVerlag.

Stein, M. K., \& Smith, M. S. (1998). Mathematical tasks as a framework for reflection: From research to practice. Mathematics Teaching in the Middle School, 3(4), 268-275. https://www.jstor.org/stable/41180401

Swedberg, R. (2012). Theorizing in sociology and social science: Turning to the context of discovery. Theory and Society, 41(1), 1-40. https://doi.org/10.1007/s11186-011-9161-5

Taylor, E., Gillborn, D., \& Ladson-Billings, G. (Eds.). (2009). Foundations of critical race theory in education. Routledge.

Van de Walle, J. A., Karp, K. S., \& Bay-Williams, J. M. (2012). Elementary and middle school mathematics: Teaching developmentally (8th ed. ed.). Pearson.

van den Heuvel-Panhuizen, M., \& Elia, I. (2012). Developing a framework for the evaluation of picture books that support kindergartners' learning of mathematics. Research in Mathematics Education, 14(1), 17-47. https://doi.org/ $10.1080 / 14794802.2012 .657437$

van Hiele (1986). Structure and insight: A theory of mathematics education. Academic Press.

Von Glasersfeld, E. (1991). An exposition of constructivism: Why some like it radical. In G. J. Klir (Ed.), Facets of systems science (pp. 229-238). Springer.

Wager, A. A., \& Parks, A. N. (2014). Learning mathematics through play. In L. Brooker, M. Blaise, \& S. Edwards (Eds.), The SAGE handbook of play and learning in early childhood (pp. 216-227). SAGE Publications Ltd.

Ward, J. M., Mazzocco, M. M., Bock, A. M., \& Prokes, N. A. (2017). Are content and structural features of counting books aligned with research on numeracy development? Early Childhood Research Quarterly, 39, 47-63. https://doi. org/10.1016/j.ecresq.2016.10.002

Watts, T. W., Duncan, G. J., Siegler, R. S., \& Davis-Kean, P. E. (2014). What's past is prologue: Relations between early mathematics knowledge and high school achievement. Educational Research, 43(7), 352-360. https://doi.org/10.3102/ 0013189X14553660

Wernet, J. L., \& Nurnberger-Haag, J. (2015). Toward broader perspectives of young children's mathematics: Recognizing and comparing Olivia's beliefs and activity. Contemporary Issues in Early Childhood Education, 16(2), 118-141. https://doi.org/10.1177/1463949115585442

Yilmaz Genc, M. M., Akinci Cosgun, A., \& Pala, S. (2017). A study of mathematical content provided in illustrated children's books. Eurasian Journal of Educational Research, 17(69), 159-175. https://doi.org/10.14689/ejer.2017.69.9 